\title{
The turbulence effect on a lean premixed methane-air flame in a Bunsen burner
}

\author{
M. S. Boulahlib ${ }^{1}$, M. Chekired ${ }^{2} \&$ S. Boukebbab ${ }^{1}$ \\ ${ }^{1}$ Laboratoire Ingénierie des Transports et Environnement, \\ Université Constantine 1, Algeria \\ ${ }^{2}$ Laboratoire d'Energétique Appliquée et Pollution, \\ Université Constantine 1, Algeria
}

\begin{abstract}
An experimental study of turbulence effects on combustion in an axisymetric turbulent jet in a piloted Bunsen burner is presented. The dynamic field of turbulent premixed methane-air flames in lean and stoichiometric conditions $(\varphi=0.6-1.0)$ was obtained using Particle Image Velocimetry Technique (PIV). The results show that on the burner axis, the mean velocities increase along the flame front. The turbulent kinetic energy is constant in the first third of the inner structure of the flame in unburned side, and increases later in the lean flame front. For the isothermal flow, near the burner wall, the turbulent kinetic energy is essentially produced by the mean velocity gradient. For the reactive flow case, the results show an important dissipation of turbulent kinetic energy in the central region of the jet due to the dilatation of the hot gases and at the same time, an important production of turbulent kinetic energy in the region surrounding the main jet.
\end{abstract}

Keywords: experimental, premixed combustion, turbulence grid, dynamic field.

\section{Introduction}

The reactive flows found in industry as in furnaces or gas turbine combustion chambers are mostly turbulent flows. Much effort in this field is motivated by the need to understand the interaction between turbulence and combustion phenomena that occur in these applications [1]. Damkohler conducted the first study on the influence of turbulence on the flame propagation in 1947 [2]. Over the past two decades, considerable progress has been made in the experimental studies thanks 
to the development of non-intrusive optical diagnostic techniques based on powerful lasers and rapid acquisition and treatment systems [3]. The experimental research in basic configurations or near industrial configurations (transparent engine, ...) on the turbulent premixed combustion allow to determine with high precision, the various parameters involved: turbulence parameters obtained by Laser Doppler Anemometry, Particle Image Velocimetry and chemical parameters or related to the combustion obtained by Laser Induced Fluorescence, Laser Tomography [4-7]. All these experimental works are essential for a better description of the physical processes involved. One of the major challenges posed by turbulent combustion is the comprehension of the interaction between the turbulence and chemical processes. In theoretical works, Bray et al. [7], Bray et al. [8], and Libby and Bray [9] suggested that thermal dilatation and associated density variations might overcome viscous dissipation and lead to a net flame production of turbulent kinetic energy. However, Poinsot and Veynante [10] showed that the Direct Numerical Simulation did not observe this net production. Plessing et al. [11] indicated that in the flame zone, the turbulence level is slightly reduced by combustion but increases downstream to about the same level as at the burner exit. Deschamps [12] and Gagnepain [13] worked on the turbulent premixed flames on a Bunsen burner. They used grids inside the burner to generate and control the level of turbulence at its exit. Deschamps [12] compared the dynamic field of the cold jet with the reactive one. He observed an increase in the axial velocity on the axis of the burner due to the acceleration of the fluid particles at the flame front. Turbulence intensity was found to be significantly higher than that existing in the non-reactive jet. Gagnepain [13] reported similar observations. However, this author has found that in the case of lean premixed flames, the axial component of the velocity fluctuation decreases at the flame front. Recently, Chekired et al. [14] were working on the simulation of flame F3 (Aachen flames). The combustion was modelled using a two-step reduced scheme of Peters and Williams. Results on the reactive and isothermal flow fields showed a good agreement between the numerical predictions and the results from the experiment.

Our study aims at well understanding the behaviour of lean flames, in order to identify what are the respective influences of turbulence on the structure of the flame and vice versa. How is the structure of the flame? What are the dominant parameters in these interaction mechanisms?

\section{Experimental set-up}

The development of optical diagnostics using lasers greatly facilitates the study of these variables. In order to understand the interfering phenomena, the chosen measuring method must be non-intrusive so as not to disturb the flame propagation and allow 2D measures. Therefore, in this study, and to measure combustion, we have chosen a measurement technique adapted to our experimental configuration, the Picture Image Velocimetry (PIV) [15-19]. This optical diagnostic measurement technique, offers the advantage of providing instantaneous and average velocity in 2D mapping. This will be used to understand how locally velocity affects the flame propagation. PIV has been applied to determine the 
aerodynamic characteristics of the flow in reactive and non-reactive case. We will present the experimental set-up: description of used burner, other set-up components, the studied flow and flame characteristics (lean, turbulent premixed, etc.), also, we will discuss in detail the techniques of chosen optical diagnostics to specify the areas of application, the identified properties and the adaptation of these techniques.

\subsection{Bunsen burner}

The experiments were carried out on a axisymmetric turbulent Bunsen burner $[3,4]$ with a stochiometric pilot flame $(\varphi=1.0)$ and a methane-air main jet $(\varphi=0.6 \div 1.0)$. The mean velocity of the central jet has a Reynolds number (based on the burner diameter) of 10,000 . The grids must introduce the turbulence created in the flame where it is necessary to remove the turbulence of the fresh gas mixture. The Coflow is used to surround the reactive flow with an inert flow of the same speed to avoid the shear between the burnt gases and air [20]. Experimental data are obtained from a turbulent conical premixed flame, stabilized by a pilot flame on a burner Bunsen (figure 1): Burner nozzle and pilot flame have respectively a diameter of 30 and $36 \mathrm{~mm}$. The air coflow can wrap the flame to avoid any lateral movements. The zirconium oxide particles, as seeding are most relevant to our study.

Table 1: Features geometric grids.

\begin{tabular}{|l|l|l|l|l|l|}
\hline Grid & $\mathrm{M}(\mathrm{mm})$ & $\mathrm{d}(\mathrm{mm})$ & $\mathrm{d} / \mathrm{M}$ & $\sigma(\%)$ & $\mathrm{C}_{\mathrm{D}}(\%)$ \\
\hline $\mathrm{P}$ & 2.40 & 2 & 0.83 & 0.38 & 37.5 \\
\hline $\mathrm{M}$ & 3.52 & 3 & 0.85 & 0.34 & 26.5 \\
\hline $\mathrm{G}$ & 4.54 & 4 & 0.88 & 0.30 & 18.4 \\
\hline
\end{tabular}

\subsection{Particle Image Velocimetry}

The principle of PIV $[15,16]$ is to replace the direct measurement of the flow velocity by the velocity of transported small particles (Zirconium oxide). To do so, the studied flow is seeded by enough fine particles to be able to locally identify their velocity to that of the flow. A Nd: YAG laser at $532 \mathrm{~nm}$, illuminates the flow at to two successive moments. A camera collects two images of the enlightened particles field $[21,22]$. Thus, the particles on the pictures were displaced between the two moments of registration, the local velocity of the particles can be numerically determined. For this, a cross correlation algorithm is successively applied on several parts of the image cut into mesh calculation. The cross correlation function presents a maximum which position in relation to the centre of the mesh calculation gives direction and value of displacement is most likely. Knowing the time between the two images and optical zoom system acquisition, the particles velocity in all areas of analysis can be calculated. This gives the velocity field throughout the study area. 


\subsection{Lines and benchmark}

\subsubsection{Burner (mm)}

The vertical axis is the y-axis; the horizontal axis in the study plan will be the r-axis (figure 1). The same is applied to velocity: the components of axial and radial velocity will be noted $v$ and $u$ respectively. The third component $(w)$ is supposed to be equal to $\mathrm{v}$, so $\mathrm{v}=\mathrm{w}$ and $\mathrm{v}^{\prime}=\mathrm{w}$ '

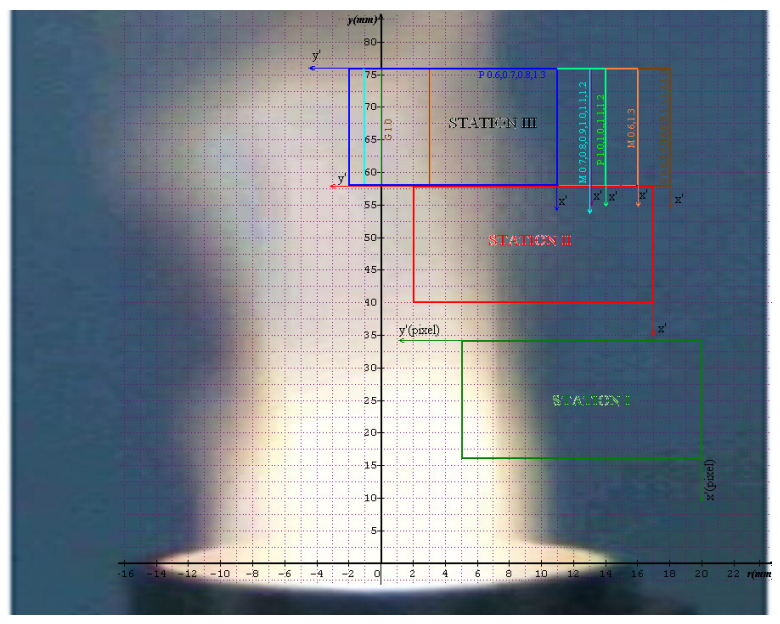

Figure 1: Area study.

\section{Results (U, V) and its fluctuations (u', v')}

Figures 2, 3, 4 and 5 illustrate the radial variation of the components of axial and radial velocity, and its fluctuations for the equivalence ratio $(\varphi=0.8)$ at different positions (axial position) (16 to $76 \mathrm{~mm}$ ). The profiles show that the mean values of velocity and its fluctuations are proportional to the distance (y).

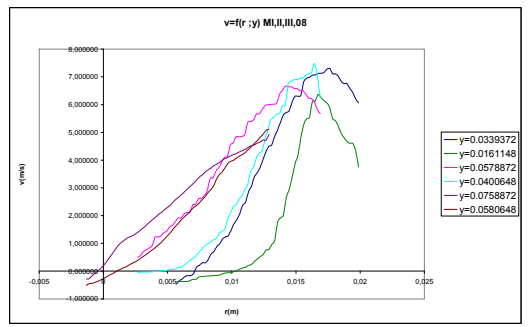

Figure 2: Radial component of the velocity $\mathrm{V}$ for $\varphi=0.8$ at different positions (station II).

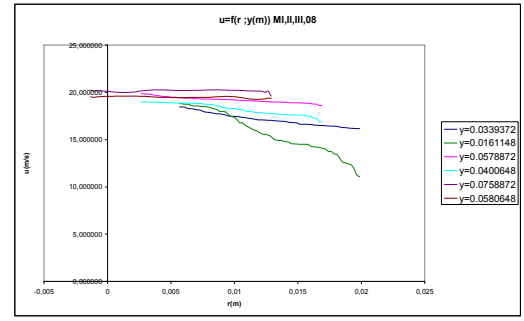

Figure 3: Axial component of the velocity $U$ for $\varphi=0.8$ at different positions (station II). 


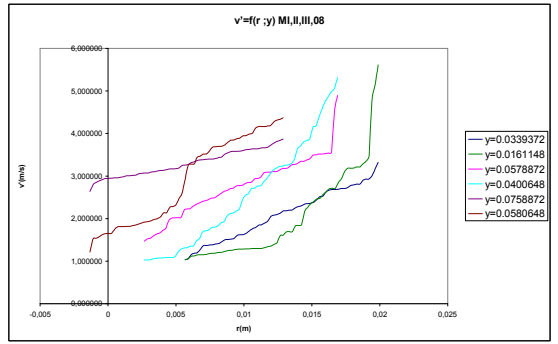

Figure 4: Radial component of the of the velocity fluctuation u' for $\varphi=0.8$ at different positions (station II).

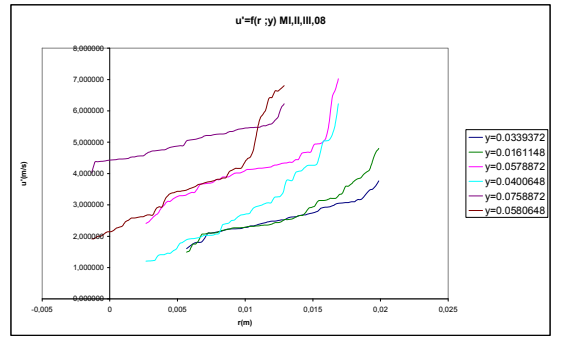

Figure 5: Axial component of the of the velocity fluctuation $\mathrm{v}$ ' for $\varphi=0.8$ at different positions (station II).

The profiles can be divided into two zones: a zone of preheating $(\mathrm{r}<13 \mathrm{~mm}$ for the station I, r $<9 \mathrm{~mm}$ for the station II, $\mathrm{r}<2 \mathrm{~mm}$ for the station III), and a reaction zone $(r>13 \mathrm{~mm}$ for Station $\mathrm{I}, \mathrm{r}>9 \mathrm{~mm}$ for the station II, $\mathrm{r}>2$ for the station III). The flame front lies at $\mathrm{r} \cong 15$ at $18 \mathrm{~mm}$ for $\mathrm{y}<35 \mathrm{~mm}, \mathrm{r} \cong 12$ at $14 \mathrm{~mm}$ for $35<\mathrm{y}<60$ and $\mathrm{r} \cong 6-8 \mathrm{~mm}$ for $\mathrm{y}>60 \mathrm{~mm}$.

Figures 6, 7, 8, 9 and 10 illustrate the radial profiles of axial and radial velocity components and its fluctuations, for the three turbulence grids $\mathrm{P}, \mathrm{M}$, and $\mathrm{G}$, equivalence ratio equal to a 0.8 and $y=33.93 \mathrm{~mm}$. The velocity profiles show that they are similar; the curves of the radial component $u$ are almost coherent. The turbulence does not influence the radial component $u$.

For other graphs (v, u', v') it is clear that the profiles of the grid P and $\mathrm{M}$ are almost the same, this means that the grids $\mathrm{P}$ and $\mathrm{M}$ have similar turbulence characteristics. Velocity obtained using $\mathrm{P}$ and $\mathrm{M}$ grids is larger than the velocity of $\mathrm{G}$ grid. The grid, which gives the greatest velocity, is the grid, which has the smallest (d/M).

The flame front moves according to the grid turbulence, it locates at $r \cong 18 \mathrm{~mm}$ for the $\mathrm{P}$ and $\mathrm{M}$ grids and at $\mathrm{r} \cong 16 \mathrm{~mm}$ for $\mathrm{G}$ grid.

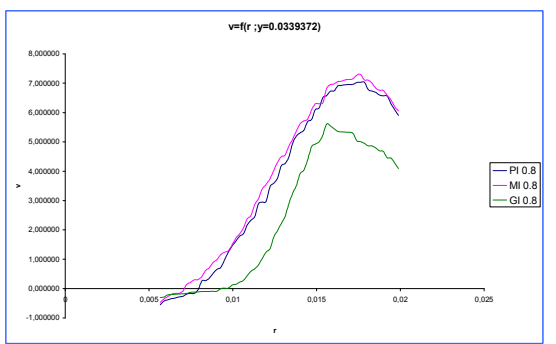

Figure 6: Axial velocity $U$ for $\varphi=$ 0.8 and different grids turbulence $\mathrm{y}=33 \mathrm{~mm}$ (station I).

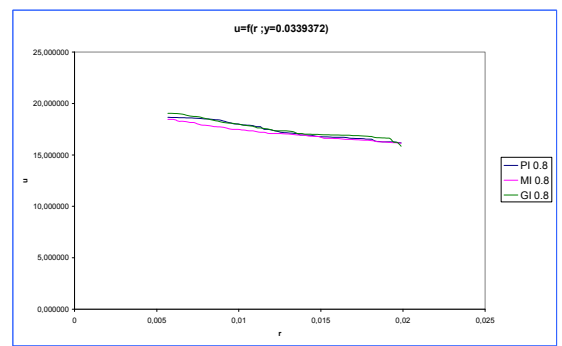

Figure 7: Radial velocity $\mathrm{V}$ for $\varphi=0.8$ and different grids turbulence $\mathrm{y}=33 \mathrm{~mm}$ (station I). 


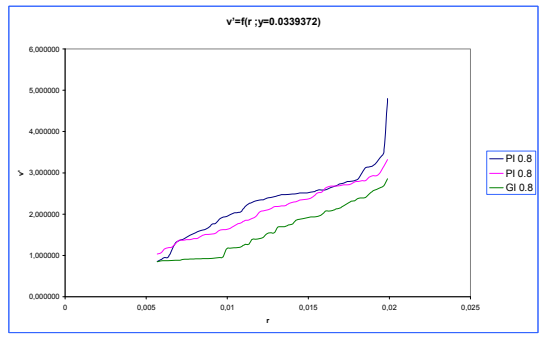

Figure 8: Radial component of velocity fluctuation $\mathrm{v}$ ' $(\varphi=0$.8) for different turbulence grids $\mathrm{y}=33$ mm (station I).

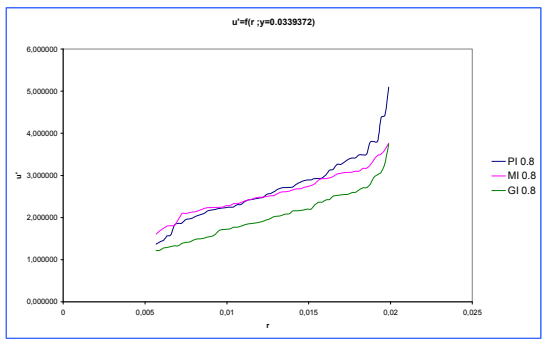

Figure 9: Axial component of velocity fluctuation $\mathrm{u}$ ' $(\varphi=0$.8) for different turbulence grids, $\mathrm{y}=33$ $\mathrm{mm}$.

\subsection{Isotropy (u'/v')}

The obtained profiles show that they are similar to each turbulence grid. The average values of the isotropy are proportional to the distance (y); isotropy increases with the height of the flame (figure 10).

The profiles show that they are similar; grid $G$ is the one that has the most important isotropy. The $\mathrm{M}$ grid has a weaker isotropy than the $\mathrm{G}$ grid. The $\mathrm{P}$ grid has the lowest isotropy (figure 11). The grid, which has the most important isotropy, is the grid with the largest ratio $(\mathrm{d} / \mathrm{m})$.

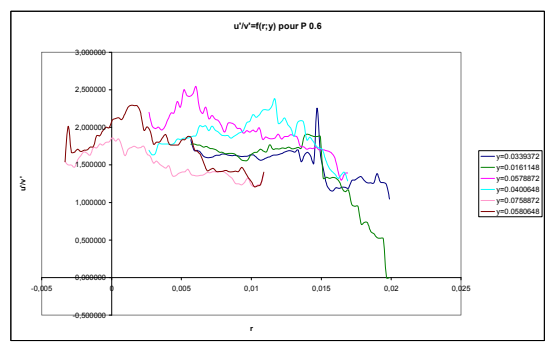

Figure 10: Isotropy u'/v' for $\varphi=$ 0.6 and for $\mathrm{P}$ grid and $\mathrm{y}=34-58 \mathrm{~mm}$

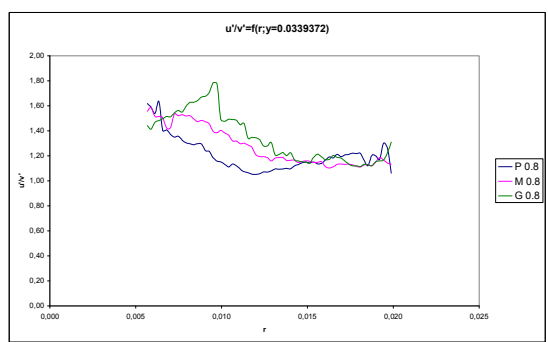

Figure 11: Isotropy $\mathrm{u}^{\prime} / \mathrm{v}$ ' for $\mathrm{P}, \mathrm{M}$ and G grids, $\varphi=0.8$ and $y=34$ $\mathrm{mm}$.

\subsection{Turbulence intensity (u'/U) and kinetic energy}

The examination of these profiles shows that they are similar to each turbulence grid. The average values of the turbulence intensity are proportional to the distance (y). The profiles can be divided into two areas: Preheat zone $(\mathrm{r}<13 \mathrm{~mm}$ for the station I, $r<9 \mathrm{~mm}$ for the station II, $\mathrm{r}<2 \mathrm{~mm}$ for the station III). Reaction zone $(\mathrm{r}>13 \mathrm{~mm}$ for the station I, $\mathrm{r}>9 \mathrm{~mm}$ for the station II, $\mathrm{r}>2 \mathrm{~mm}$ for the station III (figure 12). 


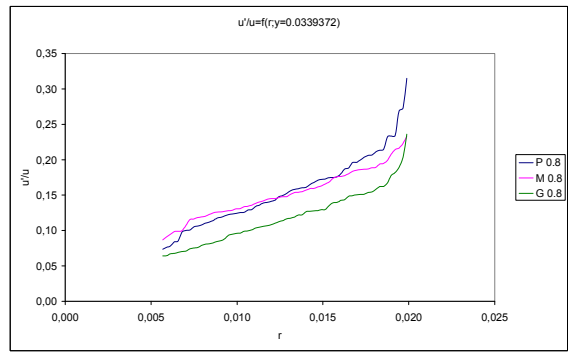

Figure 12: Turbulence intensity $\mathrm{u}^{\prime} / \mathrm{U}$ for the three grids $\mathrm{P}, \mathrm{M}$ and $\mathrm{G} \varphi=0.8$ and $\mathrm{y}=33.93 \mathrm{~mm}$ (station II).

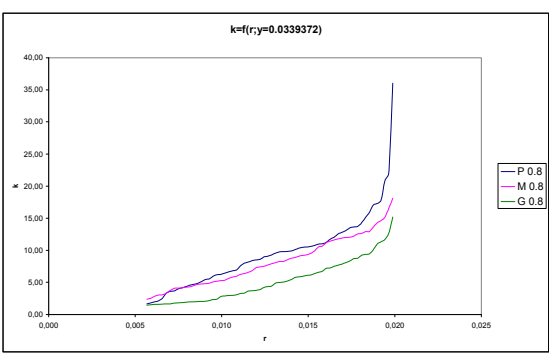

Figure 13: Kinetic energy for the $\mathrm{P}$, $\mathrm{M}$ and $\mathrm{G}$ grids, $\varphi=0.8$ and $\mathrm{y}=33.93 \mathrm{~mm}$ (station II).

The obtained profiles show that they are similar; P grid has the largest kinetic turbulent energy. $\mathrm{M}$ grid has a bit weaker kinetic energy turbulent than that of the $\mathrm{P}$ grid (figure 13). The $\mathrm{G}$ grid has the lowest kinetic turbulent energy. The grid that has the largest kinetic turbulent energy has the smallest $(\mathrm{d} / \mathrm{m})$.

\section{Conclusion}

This work reports a study of the dynamic field in a turbulent premixed lean flame, and shows the turbulence-flame interaction. A range of equivalence ratios and turbulence intensities has demonstrated these interactions. The mean velocities and its fluctuations are proportional to the distance (y). The turbulence does not influence the radial component $\mathrm{u}$. The grids that give the greatest velocity is the grid that has the smallest $(\mathrm{d} / \mathrm{M})$. M grid has a bit weaker turbulent kinetic energy than that of the $\mathrm{P}$ grid. The $\mathrm{G}$ grid has the lowest turbulent kinetic energy. The grid that has the largest turbulent kinetic energy has the smallest $(\mathrm{d} / \mathrm{m})$. The PIV technique that uses zirconium oxide as a marker seems to be more suitable for our case.

\section{Nomenclature}

$\mathrm{R}$ : radius of the burner $(\mathrm{m})$

$\mathrm{Y}$ : axial direction $(\mathrm{m})$

$\mathrm{X}$ : radial direction $(\mathrm{m})$

$\mathrm{U}$ : radial velocity $(\mathrm{m} / \mathrm{s})$

$\mathrm{V}$ : axial speed $(\mathrm{m} / \mathrm{s})$

u': fluctuation radial $(\mathrm{m} / \mathrm{s})$

$\mathrm{v}$ ': axial fluctuation $(\mathrm{m} / \mathrm{s})$

$\mathrm{u}$ '/U: the intensity of turbulence

u'/v': isotropy

$\mathrm{K}$ : the turbulent kinetic energy $(\mathrm{m} 2 / \mathrm{s} 2)$

$\mathrm{r}$ : radial direction $(\mathrm{m})$

$\mathrm{Y}$ : the axial direction (m) 


\section{Acknowledgements}

The authors gratefully acknowledge technical support by the Coria laboratory of Rouen (France). The authors also thank A. M. Boukhalfa (Coria Rouen) for the stimulating discussions, B. Renou (Combustion Diagnostics Group Coria Rouen) for their help in setting up and operating the laser system, and B. Taupin, O. Desgardin, G. Martins and C. Lacour (Coria Rouen, France) for his help in developing part of the image post-processing routine.

\section{References}

[1] Miles P.C. and Gouldin F.C., "Mean reaction rates and flamelet statistics for reaction rate modeling in premixed turbulent flames" $24^{\text {th }}$ Symposium (international) on Combustion, The Combustion Institute, pp. 477-484, 1992.

[2] Damkohler K. "The effect of turbulence on the flame velocity in a gas mixture” NACA TM 1112, April 1947.

[3] Boulahlib M.S., Renou B, Taupin B., Boukhalfa A. \& Nemouchi Z., "Experimental study of the influence of the equivalence ratio and turbulence on CH4-air premix flame in a Bunsen burner using Laser tomography" science and technology, Series B, University Mentouri Constantine (No. 22B, December 2004).

[4] Boulahlib M.S., Boukebbab S., Amara I. \& E. Ferkous, "Scalar characteristics of lean premixed turbulent V-shape flame (air-butane)", WIT Transaction on Engineering Sciences, pp. 37-47, Volume 61, 2008.

[5] Borghi R., Destriau M., “Combustion et flammes”, Technip, Paris 1995.

[6] Bradly D. and Matthews K. J., "Measurement of high gas temperatures with wire thermocouple”, Mechanical Engineering Science, Vol. 10(4), 1968.

[7] Bray K.N.C., Libby P.A., Masuya, G., and Moss J.B., "Turbulence production in premixed turbulent flames", Combustion Science and Technology. 25: 127-140, 1981.

[8] Bray K.N.C., Champion M. and Libby P.A., "Mean reaction rates in premixed turbulent flames" $22^{\text {th }}$ Symposium (international) on Combustion, The Combustion Institute, pp. 763-769, 1988.

[9] Libby P.A., and Bray K.N.C., "Countergradient diffusion in premixed turbulent flame”, AIAA J., vol. 19, 205-213, 1981.

[10] Poinsot T., Veynante D., "Theoretical and numerical combustion”, R.T. Edwards, 2001.

[11] Plessing T., Kortschik C., Peters N., Mansour M.S., Cheng R.K., Measurements of the turbulent burning velocity and the structure of premixed flames on a low-swirl burner, Proceedings of the Combustion Institute, Volume 28, Issue 1, 2000, pp. 359-366.

[12] Deschamps B., "Etude spatiale et temporelle de la structure dynamique et scalaire des flammes turbulentes prémélangées de méthane-air”, Thèse de Doctorat, Université d'Orléans, 1990. 
[13] Gagnepain L., "Contribution à l'étude de la structure des flammes turbulentes prémélangées pauvre. Détermination des échelles caractéristiques des champs dynamique et scalaire ». Thèse de Doctorat, Univ. d'Orléans, 1998.

[14] Chekired M., Nemouchi Z., and Boulahlib M.S., Numerical Investigation of Turbulent Premixed Methane/Air Jet Flame Using Peters and Williams Reduced Mechanism, Int. J. Fluid Mech. Res., Vol. 41, No. 1, 2014.

[15] Adrian R.J., Yao C., "Scattering particle characteristics and their effect on measurement of pulsed laser speckle fluid flow velocimetry vs particle image velocimetry" Applied Optics, No. 23, pp. 1690-1699 1984.

[16] Bingham D.C., Gouldin F.C., \& Knaus, D.A., "Crossed Tomography Laser-plane: Direct Measurement of the Surface flamelet Normal", Twenty-seventh (International) Symposium on Combustion/The Combustion Institute, pp. 77-84, (1998).

[17] Jeanne B., Samson E., Renou B. \& Boukhalfa A., "Bunsen flame simulatneous analysis using tomographic images and VIPs in the fresh and burnt gases" 9th International Symposium on Flow Visualization, HeriotWatt University, Edinburgh, GM Editor Carlomagno and I. Grant pp. 376-1004, 2000

[18] Rouland E., "Study and development of the technique of cross vélocimétrie by images of particles. Application to hydrodynamic flow in the tunnel" $\mathrm{Ph} . \mathrm{D}$. thesis, Universite de Rouen, 1994.

[19] Zhang Y., Chew T.C. and Bray K.N.C., Paper presented at "displacement particle image velocimetry" lecture series, Von Karman Institute for Fluid Dynamics, Belgium (1988).

[20] Pavé D., "Contribution to the study of the structure of flames turbulent premixed lean methane-air", Ph. D. thesis. University of Orleans (2002).

[21] Boyer L. "Laser tomograhic method for flame front movement studies" Combustion and Flame 39: 321-323 (1980).

[22] Lecordier B., "Study of the interaction of the spread of a premixed flame with the aerodynamic field by association tomography laser and the vélocimétrie particle image”: Ph.D. thesis. University of Rouen, 1998. 